\title{
Longitudinal Study of High and Low Functioning Preschool Children with ASD and the Progress Made Following Therapeutic Intervention
}

\author{
Kotsopoulou Angelique, Georgiou Anastasia, Gyftogianni Aikaterini, Gyftogianni Maria, Florou Irene, \\ Palaiodimou Eleonora, Troupou Antigoni, Koumanioti Efthimia \\ Day Centre for Children with Developmental Disorders, Messolonghi, Greece
}

\begin{abstract}
The present study addresses three problem areas among preschool children with ASD (Autism Spectrum Disorder): co-occurring psychiatric problems, speech-language and feeding difficulties, and progress of low functioning (globally retarded) children in most areas of development. Fifty children with ASD (mean age 3 years) were studied. Three therapists of different disciplines (the first to see and treat the children) examined carefully the files of the children, tests, notes and $\mathrm{E} \Delta \mathrm{A} \Lambda \Phi \mathrm{A}$ (special multidisciplinary tool) to classify the problems of the children. All children presented with co-occurring psychiatric problems such as: externalization $74 \%$, ADH 54\%, internalization $52 \%$. Children in the average intelligence presented with higher levels of ADH (attention deficit hyperactivity problems) difficulties. Most children presented more than two co-morbitities, but contrary to our hypothesis, low functioning children presented with fewer co-morbitities. Four speech language pathologists (those who saw and evaluated the children when they were first enrolled in therapy) after meticulous study of the children's files, notes, tests and $\mathrm{E} \triangle \mathrm{A} \Lambda \Phi \mathrm{A}$ records found the following: all children (100\%) presented with receptive and expressive language problems, a high proportion (64\%) had developmental dyspraxia (verbal and oral), 18\% never developed speech (all of them had oral dyspraxia), 28\% had phonological disorder and $28 \%$ feeding difficulties. Thirty two children received therapy for almost two years (mean 21.90 months) and had one to three $\mathrm{E} \Delta \mathrm{A} \Lambda \Phi \mathrm{A}$ re-evaluations. The average range of progress made ranged from 15.41 months (psychosocial development) to 26.34 months (everyday living skills). Even children globally retarded (RAVEN $<60$ ) made progress 4.63 months (expressive language) to 18.57 months (cognitive development). Intelligence and receptive language skills were highly correlated with progress.
\end{abstract}

Keywords: ASD (Autism Spectrum Disorder), preschool children, co-occurring psychiatric problems, language deficits, therapy, progress, high and low functioning children

Kotsopoulou Angelique, Ph.D., Associate Professor, Day Centre for Children with Developmental Disorders. Georgiou Anastasia, Sociologist, Day Centre for Children with Developmental Disorders. Gyftogianni Aikaterini, Speech language therapist, Day Centre for Children with Developmental Disorders. Gyftogianni Maria, Speech language therapist, Day Centre for Children with Developmental Disorders. Florou Irene, Ph.D., Psychologist, Day Centre for Children with Developmental Disorders.

Palaiodimou Eleonora, M.Sc., Psychologist, Day Centre for Children with Developmental Disorders. Troupou Antigoni, Speech language therapist, Day Centre for Children with Developmental Disorders. Koumanioti Efthimia, MBA, Economist, Day Centre for Children with Developmental Disorders. 


\section{Introduction}

The positive effect of early intervention in children with ASD is well established in the literature (Rogers \& Dawson, 2010; Koegel \& Koegel, 2006; Vivanti, Dissanayake, \& the Victorian ASELCC Team, 2016; Fernell, Eriksson, \& Gillberg, 2013). However, while there is enough information about the positive effect of therapy to the high functioning children with ASD, very little is known about the progress of low functioning children with global retardation (Boucher, 2011; Rivard, Terroux, Mercier, \& Parent-Boursier, 2015). There is, also, limited information on the psychosocial profile and the co-occurring psychiatric difficulties of children below four and little information on the exact speech, language and feeding difficulties that the preschool children with ASD present. Functions such as intelligence, degree of autism, language, and environment have been identified to influence progress (Mukaddes et al., 2014; Ben-Itzchak, Watson, \& Zachor, 2014; Rivard et al., 2015). Do these factors play the same role in the progress of low functioning children? We will try to elicit some answers to these questions.

\section{Preliminary Information on the Study}

The sample of the children came from the Day Centre of the Society of Mental Health for Children and Adolescents of Aitoloakarnania. It is the only centre of its kind in Western Greece highly evaluated by the Ministry of Health. It keeps employing 12 permanent staff ( 2 psychiatrists, 2 psychologists, 2 social workers, 4 speech language pathologists, 1 full-time and 1 part-time occupational therapists, 1 special educational teacher, and a volunteer gymnastics teacher). The diagnosis of autism is made by the psychiatrists and psychologists of the Centre by clinical observation and up to date tools such as ADOS, Vineland, CARS (childhood autism rating scale), ACQ, translated into Greek, as well as by referral to hospitals for further testing when necessary. The level of functioning of each case and the placement of therapy targets are performed by the multidisciplinary team using a specific tool developed by the team, known as $\mathrm{E} \Delta \mathrm{A} \Lambda \Phi \mathrm{A}$ (Kotsopoulou et al., 2014).

\section{Description of $\mathbf{E} \Delta \mathrm{A} \Lambda \Phi A$}

$\mathrm{E} \triangle \mathrm{A} \Lambda \Phi \mathrm{A}$ has been presented in two international conferences IALP (2010), INFAR (2013) and was published in the journal Psychology Research (2014). It is a tool for the multidisciplinary team to assess the child on important psycholinguistic and motor functions, which would allow them to set joint realistic treatment goals. It contains a scale of detailed information on the development of typically developing children on the following functions: motor (gross and fine), cognitive, language (receptive and expressive), psychosocial skills, everyday skills (feeding, dressing, toilet training), play and other (joint attention, imitation, stereotypes). The different skills a typically developing child is supposed to master are recorded for every month for the first year of life, every two months until the age of two years old, every 6 months till the age of three years old and every year till the age of six. The developmental level of the child with autism is compared with that of typically developing children in order to determine his/her profile, which would direct the treatment team to set realistic therapeutic goals for the intervention. The developmental scale was based on five international scales (Zimmerman, Steiner, \& Pond, 1992; Hindley, 1960; Bzoch \& League, 2000; Mecham, 1958; Arverson \& Brodsky, 2002; Fewell \& Folio, 2000) and systematic review of the recent literature for inclusion of skills was identified as important in the development of the child (e.g., joint attention, imitation, stereotypies etc.). After a period of time, according to the case, not exceeding 4 months of observation, three therapists of different disciplines involved in the case, meet and complete the profile of the child. The goals of therapy are set automatically in a hierarchical developmentally way (see Figure 1 and explanation of evaluations). 
The present longitudinal study includes three studies and investigates the following: (a) the initial psychosocial profile of the children and the co-occurring psychiatric difficulties they presented; (b) detailed description of their speech, language and feeding difficulties at the time of their acceptance to the program; and (c) the progress both high and low functioning children made and the factors that influenced best their progress.

\begin{tabular}{|l|l|l|}
\hline Evaluations & & \\
\hline Functions & 1 st Evaluation at 38 months & Re-evaluation at 47 months \\
\hline Gross Motor & 36 & 48 \\
\hline Fine Motor & 36 & 48 \\
\hline Cognitive & 24 & 36 \\
\hline Receptive Language & 18 & 36 \\
\hline Expressive Language & 18 & 30 \\
\hline Psychosocial & 22 & 30 \\
\hline Skills of Everyday Life & 14 & 30 \\
\hline Play & 22 & 30 \\
\hline Other (Join Attention, Imitaqtion, Sterotypes) & 22 & 30 \\
\hline
\end{tabular}

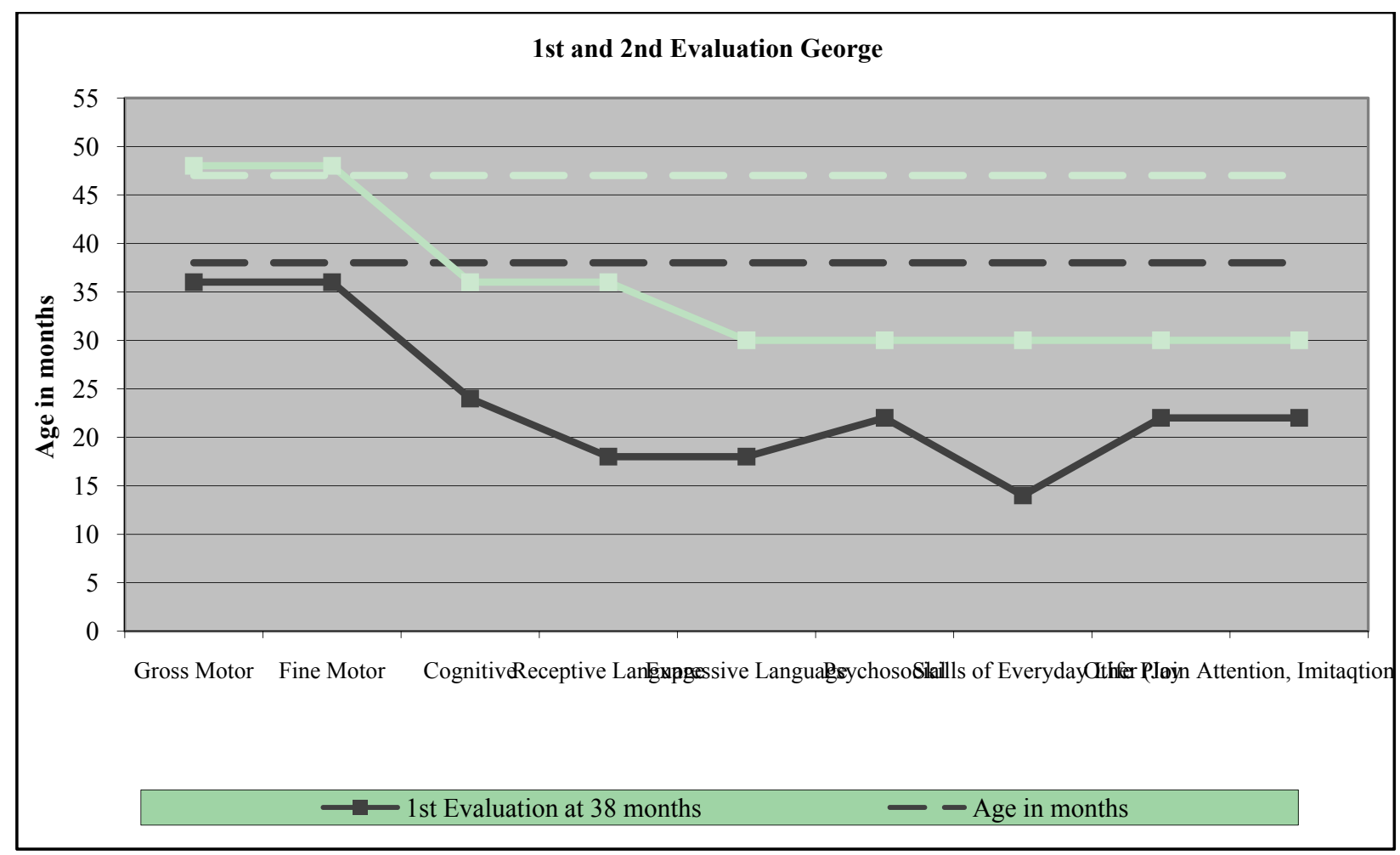

Figure 1. A sample diagram of first assessments with $\mathrm{E} \Delta \mathrm{A} \Lambda \Phi \mathrm{A}$ and re-evaluation.

\section{Co-occurring Psychiatric Difficulties}

\section{Introduction}

A number of recent studies have shown that children with ASD often present psychiatric disorders. In a study of 101 children (Salazar et al., 2015) aged 4.5-9.8 years with ASD, 90.5\% of the sample presented with the following disorders: anxiety disorder, phobias, depression, ADHD, oppositional disorder and conduct disorder. A number of studies with older children and adolescents with ASD showed also high levels of 
psychiatric problems, e.g., depression and irritability (Joshi et al., 2014; Andersen et al., 2015; Mikita et al., 2015), as well as ADHD (Levy et al., 2010). Do these co-occurring difficulties exist in very young preschool children?

\section{Methodology}

Sample. In the period 2004-2015, 71 preschool children with ASD were accepted for intensive therapy at the Centre. Of those 7 interrupted therapy, 14 did not have an $\mathrm{E} \Delta \mathrm{A} \Lambda \Phi \mathrm{A}$ completed because it hadn't yet been developed and the remaining 50 children was made to the sample of the study. The age of the children ranged from 19 months to 69 months (average 37 months or 3 years and 1 month). Greek was the mother tongue for $90 \%$ of the sample, and $10 \%$ other, mostly Albanian. They all lived in the same province, only two had previous speech and occupational therapy and their socioeconomic level was 36\% low, 44\% average and 20\% above average. For each child, CARS, which measures severity of autism, and the Raven Progressive Matrices for the evaluation of practical non verbal mental ability were completed at the initial stages of therapy (see Figure 2).

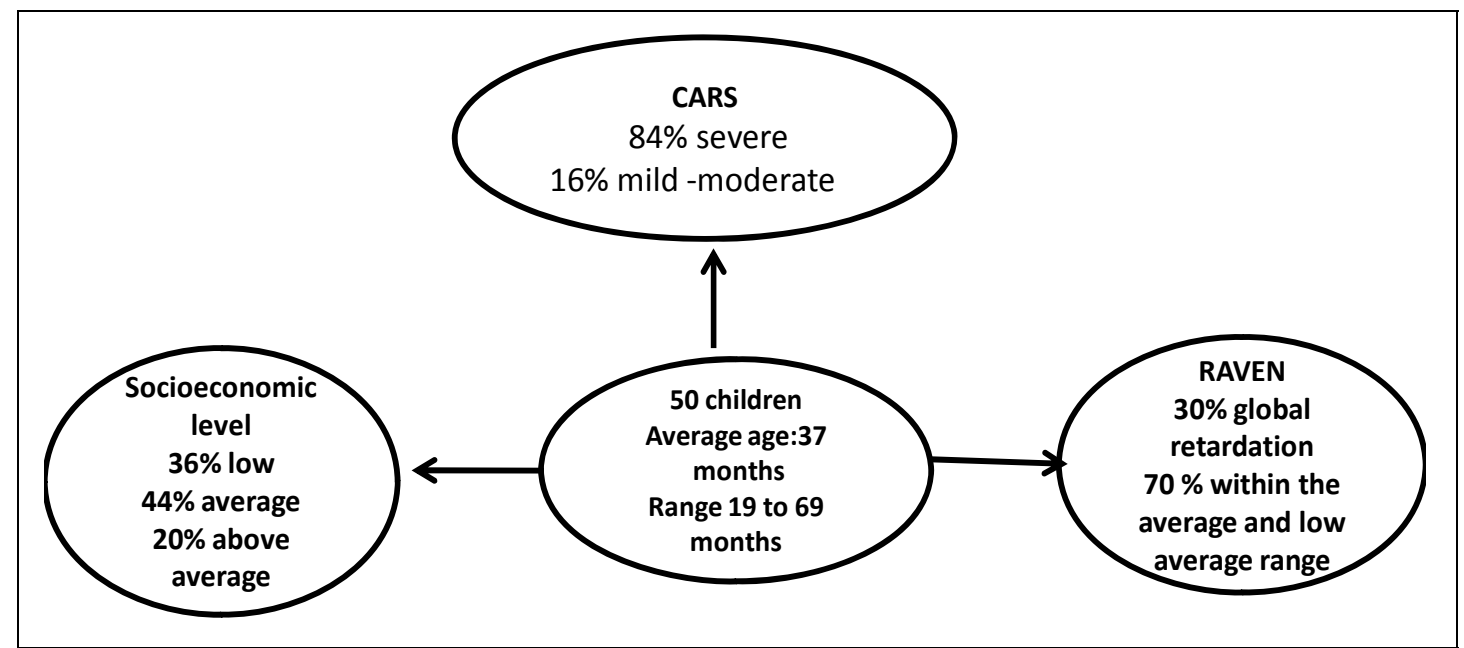

Figure 2. Characteristics of the sample at the beginning of therapy.

In order to investigate the presence of co-occurring behavioral problems that are associated with psychiatric disorders, three therapists (psychologist, social worker, speech-language pathologist), authors of this paper, investigated in detail material showing the initial psychosocial profile of the children (e.g., files of the children, psychiatric diagnosis, formal reports, $\mathrm{E} \Delta \mathrm{A} \Lambda \Phi \mathrm{A}$ profiles and notes of the different therapists). According to recent bibliography and the extensive experience and firsthand knowledge of the children by the therapists (they were the first to see and treat the children), they classified the children according to the following psychiatric problems that they presented: externalization difficulties: irritability, aggression and other (oppositional, manipulative, adjustment difficulties), ADH; internalization difficulties: anxiety, sadness, and phobias.

Two hypotheses were raised: (a) Low functioning children with ASD present more co-occurring psychiatric difficulties and (b) High functioning ASD children present more often ADH.

Statistical analysis. Descriptive statistics were used to demonstrate the co-occurring psychiatric problems in the sample, and the association with intellectual ability (see Table 1). 
Table 1

Single and Co-occurring Psychiatric Problems Among 50 ASD Children

\begin{tabular}{lll}
\hline 37 children $(74 \%)$ & 26 children $(52 \%)$ & 27 children $(54 \%)$ \\
Externalization problems & Internalization problems & ADH \\
\hline 5 children $(10 \%)$ aggression & 22 children $(44 \%)$ anxiety & \\
22 children $(44 \%)$ irritability & 6 children $(12 \%)$ phobias & \\
36 children $(72 \%)$ other problems & 3 children $(6 \%)$ other problems & \\
\hline
\end{tabular}

\section{Results}

Most children presented with co-occurring psychiatric problems: $74 \%$ externalization problems, $54 \%$ $\mathrm{ADH}$ problems and 52\% internalization problems. We should have in mind that there were children who presented both internalization and externalization problems which explains the high numbers of percentiles. Children in the average intelligence range presented with higher levels of ADH difficulties $(77.20 \%)$ than the low function ones $(26.70 \%)$. The most common problems were: ADH (54\%), anxiety $(44 \%)$ and irritability (44\%) (see Table 2).

Table 2

Number of Co-occurring Psychosocial Problem

\begin{tabular}{llllll}
\hline $\begin{array}{c}\text { Co-occurring psychosocial } \\
\text { problems in 50 children }\end{array}$ & \multicolumn{2}{c}{$\begin{array}{c}\text { Co-occurring psychosocial } \\
\text { problems in 22 children }\end{array}$} & $\begin{array}{c}\text { Co-occurring psychosocial } \\
\text { problems in 15 children }\end{array}$ \\
\hline None & $8.00 \%$ & None & $5.00 \%$ & None & $20.00 \%$ \\
\hline 1 co-morbidity & $14.00 \%$ & 1 co-morbidity & $18.00 \%$ & 1 co-morbidity & $13.30 \%$ \\
2 co-morbidity & $24.00 \%$ & 2 co-morbidity & $23.00 \%$ & 2 co-morbidity & $26.70 \%$ \\
3 co-morbidity & $32.00 \%$ & 3 co-morbidity & $27.00 \%$ & 3 co-morbidity & $13.30 \%$ \\
4 co-morbidity & $16.00 \%$ & 4 co-morbidity & $18.00 \%$ & 4 co-morbidity & $20.00 \%$ \\
5 co-morbidity & $6.00 \%$ & 5 co-morbidity & $9.00 \%$ & 5 co-morbidity & $6.70 \%$ \\
\hline
\end{tabular}

Most of the children presented more than two co-morbitities, but contrary to our hypothesis low functioning children presented with less co-morbitities and $20 \%$ had none.

\section{Speech Language and Feeding Problems}

\section{Introduction}

Delayed development of speech is observed in many children in the spectrum (Boucher, 2011; Eigsti, De Marchena, Schuh, \& Kelly, 2011), as well as difficulties in language comprehension and prosody (Plog, Banerjee, \& Brooks, 2011; Hudry et al., 2014). We also know that development of speech before the age of five is a positive factor in the development of functional speech (Tager-Fluusberg \& Kasari, 2013). Furthermore, adequate comprehension of language at two and a half years is a strong indicator of what differentiates between children who develop language and those who do not (Weismer \& Kover, 2015). Even after therapy, a number of children fail to develop speech. Although the occurrence of speech-language and feeding problems in autism is widely accepted, its prevalence in younger preschool children is still a question. According to DSM-5, speech and language disorders are accompanying rather than basic symptoms of autism. How true is this statement? The aim of the second study was to investigate in detail the occurrence of speech-language and feeding problems in the same sample of children.

\section{Methodology}

Sample. As was mentioned earlier, the sample consisted of 50 children with ASD (see Figure 1), that were accepted for intensive therapy at the Day Centre. 
Diagnosis of speech-language disorders. The diagnosis of speech and language disorders was performed during the first months of acceptance of the children at the Centre, by four speech language pathologists using clinical observation, the tool $\mathrm{E} \triangle \mathrm{A} \Lambda \Phi \mathrm{A}$ and formal tests when appropriate, like PLS-3, PPVT-III, CELF-Preschool, EOWPVT-Revised, Action Picture Test (all of them translated in Greek and used extensively at the Centre) and the Greek Test of Phonetic and Phonological Development. The four therapists, authors of the present study, were those who made the initial diagnosis, who were involved in the children's therapy and were the same therapists for all those 11 years. The description of the occurrence of speech and language disorders for this study was based on detailed and systematic review of the files of each one of the children. The speech and language disorders recorded were the following: developmental dyspraxia (oral or verbal), phonological disorder, receptive and expressive language disorder, feeding difficulties, echolalia.

Statistical analysis. Descriptive statistics were used.

\section{Results}

Table 3

Speech Language and Feeding Difficulties

\begin{tabular}{ll}
\hline Dyspraxia: $64 \%$ & $\begin{array}{l}\text { Oral dyspraxia: } 44 \% \\
\text { Verbal dyspraxia: } 20 \%\end{array}$ \\
\hline Absence of speech: $44 \%$ & \\
\hline & Mild: $4 \%$ \\
${ }^{*}$ Receptive language: $100 \%$ & Moderate: $26 \%$ \\
& Severe: $70 \%$ \\
\hline & Mild: $8 \%$ \\
${ }^{*}$ Expressive language: $100 \%$ & Moderate: $8 \%$ \\
& Severe: $84 \%$ \\
\hline Phonological disorders: $28 \%$ & \\
${ }^{* *}$ Feeding Disorders: $28 \%$ & \\
Echolalia: $30 \%$ & \\
\hline
\end{tabular}

Notes. ${ }^{*}$ included the children with absence of speech; ${ }^{* *}$ Selectivity has not been included in feeding disorders.

All children (100\%) presented with receptive and expressive language problems. A high number of them (64\%) had developmental dyspraxia (verbal and oral), 18\% never developed speech (all of them had oral dyspraxia), 28\% had phonological disorder and 28\% feeding difficulties (chewing and swallowing difficulties, selectivity had not been included in feeding disorders). Dyspraxia was present even in children with average intelligence, but these children made better progress than the low functioning ones (see Table 3).

\section{Progress the Children Made}

\section{Introduction}

As mentioned earlier, the positive effect of early intervention in children with ASD is well established in the literature. However, while there is enough information about the positive effect of therapy to high functioning children with ASD, very little is known about the progress of low functioning children with global retardation. The present study attempts to investigate this.

\section{Methodology}

Sample. In the period 2004-2015, 71 preschool children with ASD were accepted for intensive therapy at 
the Centre. Of those 7 interrupted therapy, 14 were not assessed using the $\mathrm{E} \triangle \mathrm{A} \Lambda \Phi \mathrm{A}$ tool, because it hadn't yet been developed and 18 were recently involved in therapy having only one evaluation of the $\mathrm{E} \triangle \mathrm{A} \Lambda \Phi \mathrm{A}$ and no re-evaluation. The remaining $32 \mathrm{had}$ one evaluation and two or more re-evaluations, and these made the sample of this study. The sample consisted of 32 children with average age of 3 years and 10 months (46 months) who accepted intensive therapy and were re-evaluated using the $\mathrm{E} \Delta \mathrm{A} \Lambda \Phi \mathrm{A}$ tool, approximately every year and sometimes sooner when the goals of therapy were completed. The sample was not chosen. All 32 came from the same region, had Greek as mother tongue and only six of the children came from bilingual families (Albanian) (see Figure 3).

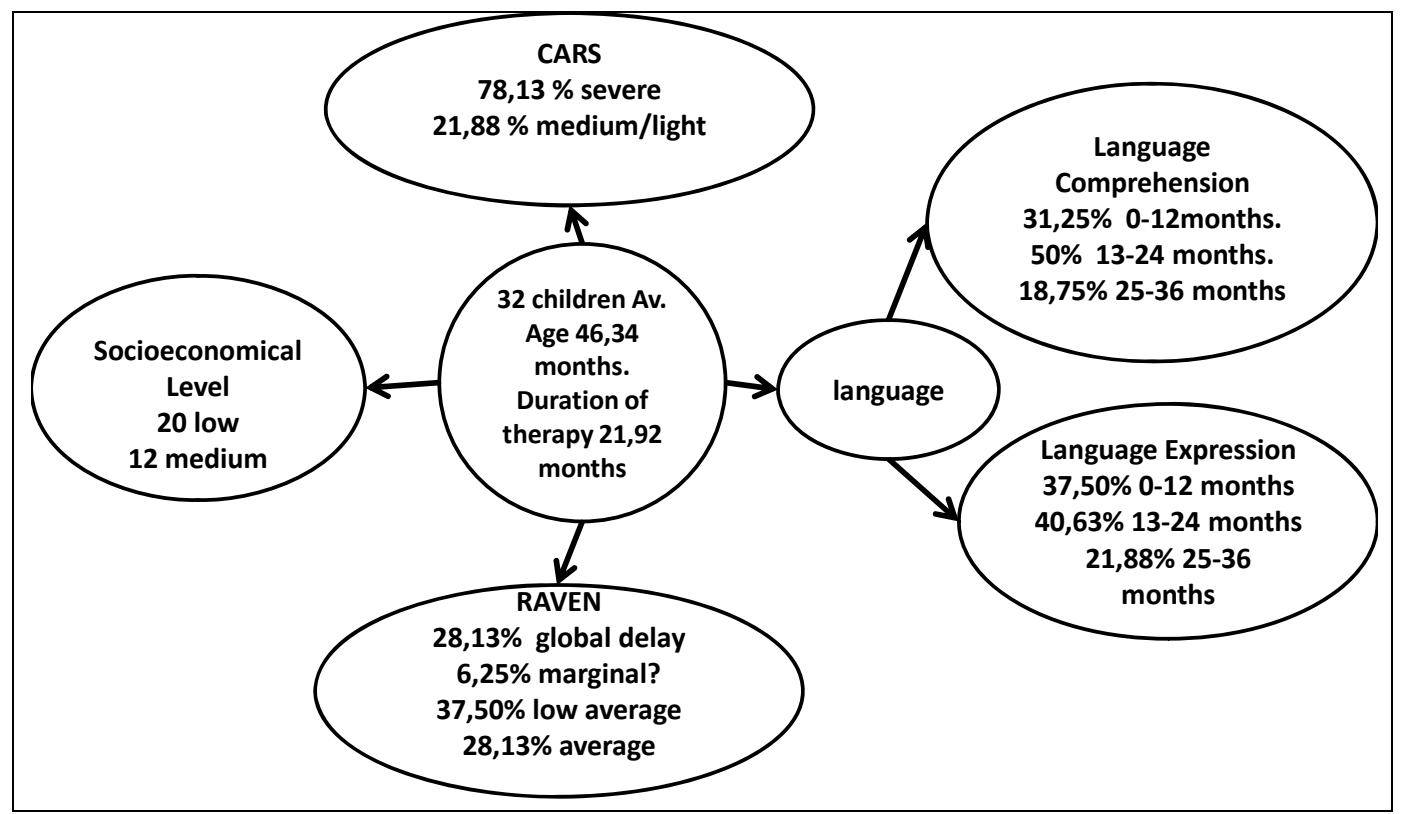

Figure 3. Initial assessment of the 32 children who received therapy.

Tests administered. As mentioned earlier, the diagnosis of autism of all children was performed at the Centre using different tests. For this study, the scores of three tests were used: CARS, RAVEN, and the tool $\mathrm{E} \triangle \mathrm{A} \Lambda \Phi \mathrm{A}$. Scores in months for all nine developmental functions of $\mathrm{E} \triangle \mathrm{A} \Lambda \Phi \mathrm{A}$ (gross and fine movements), cognitive development, speech and language development (comprehension and expression), psychosocial development (emotions-social skills), everyday skills (feeding, dressing, toilet training), play and other (joint attention, imitation, stereotypes), were calculated by the multidisciplinary team for every child. The first $\mathrm{E} \triangle \mathrm{A} \Lambda \Phi \mathrm{A}$ of each child was completed after 2 to 4 months of observation by at least 3 therapists of the main disciplines very skillful in the completion of $\mathrm{E} \triangle \mathrm{A} \Lambda \Phi \mathrm{A}$. It is worth mentioning here that all therapists remained the same over the years, except of the occupational therapists that changed twice. All these tests were given before commence of therapy. Furthermore, all of the children were re-evaluated once, twice and in some occasions three times during the period of their therapy. To find out the progress the children made, the difference between the first evaluation and the last re-evaluation of $\mathrm{E} \triangle \mathrm{A} \Lambda \Phi \mathrm{A}$ was recorded in months, as well as the duration of therapy (see Figure 5).

\section{Results}

The average range of progress in the 21.91 months of intensive therapy ranged from 15.41 months (psychosocial) to 26.34 months (everyday skills) (see Figure 5). 


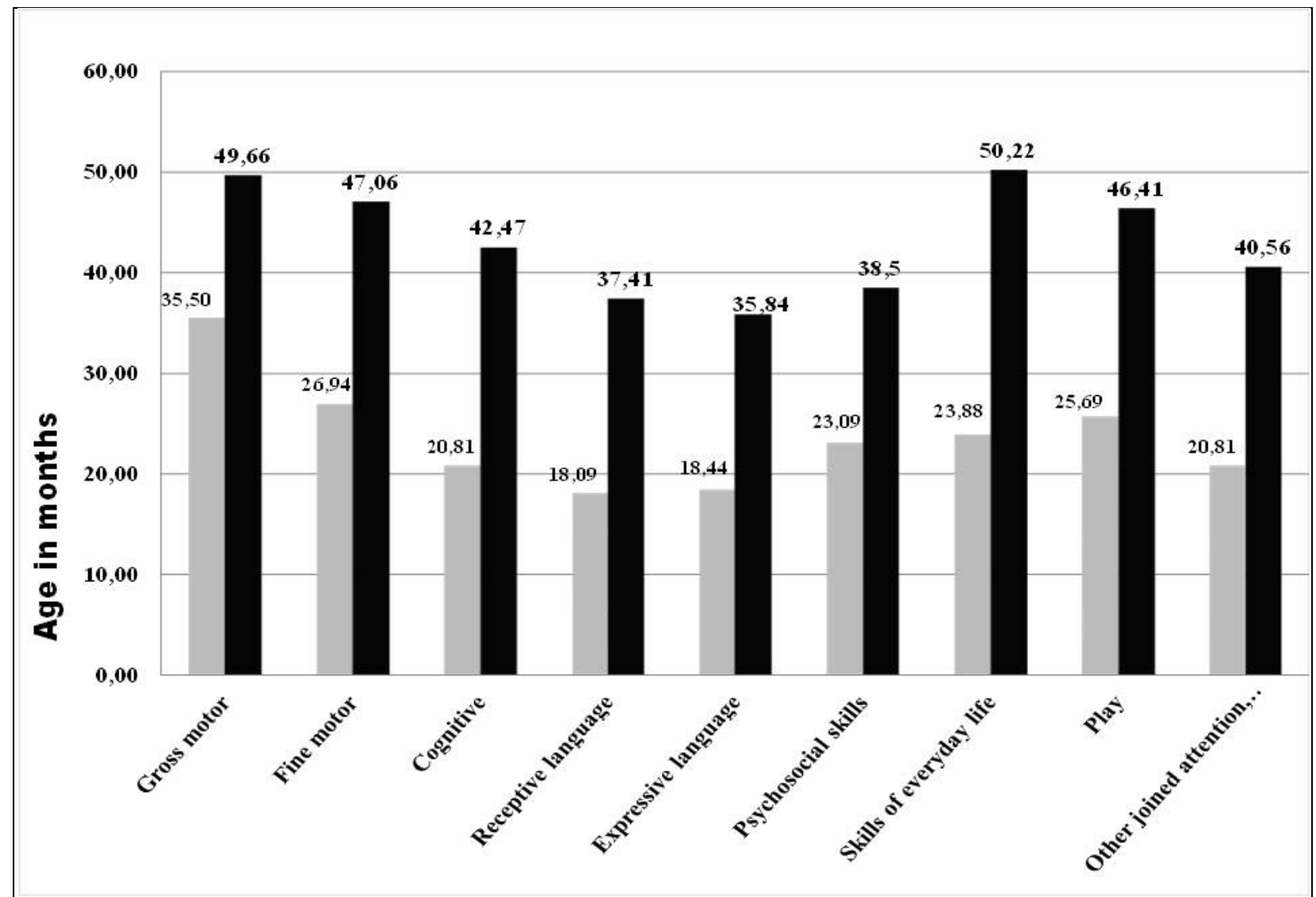

Figure 4. Initial and final evaluation of the total sample of 32 children.

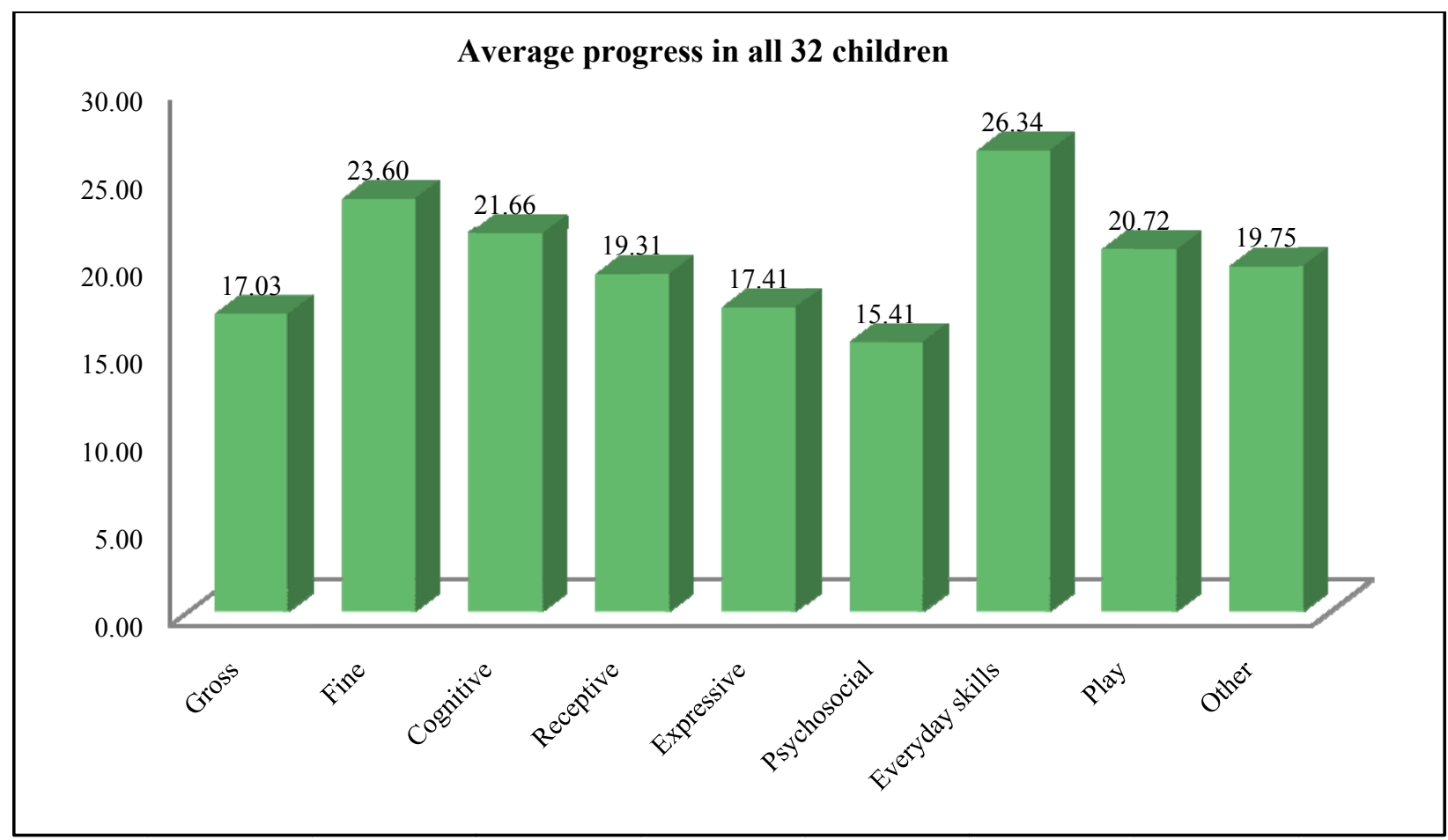

Figure 5. Average progress of the sample (32 children) over a period of 22 months. 
Even children with global retardation, intelligence quotient raven $<60$ made progress from 4.63 months (expressive language) to 18.57 months (cognitive development) (see Figure 6).

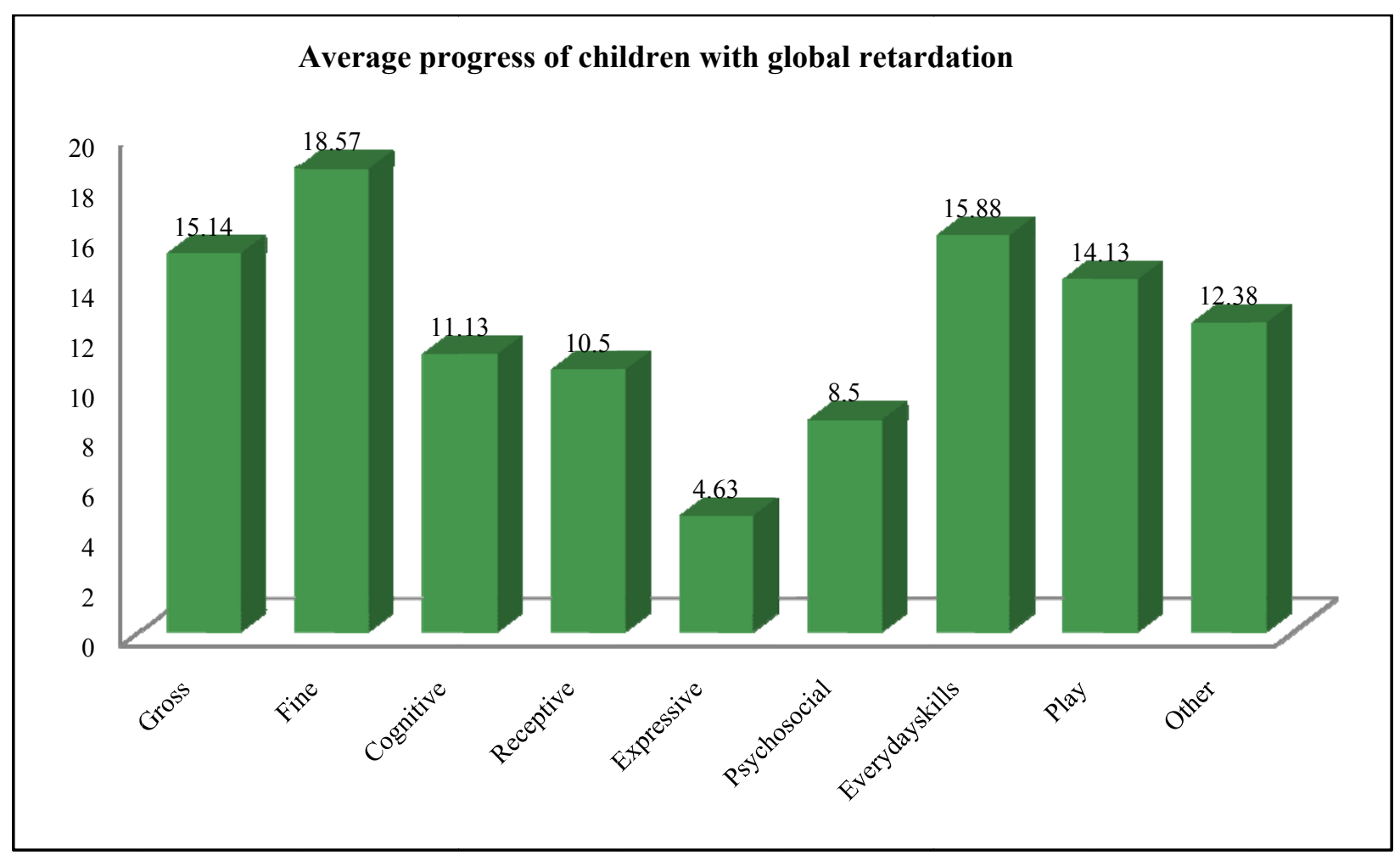

Figure 6. Average progress of 8 of the 32 children with global retardation IQ $<60$.

As mentioned in the introduction, some factors such as intelligence, severity of autism, language have been identified to influence progress positively. To verify these comments in the present study, the scores of the tests CARS, RAVEN, Language Comprehension (LC) and Language Expression (LE) as well as duration of therapy (DTH) were compared with the scores of the remaining $\mathrm{E} \triangle \mathrm{A} \Lambda \Phi \mathrm{A}$ progress scores in each one of the 9 categories. According to Luyster (2009), the number of studies with receptive language measures is limited and the most reliable method of assessment is the multi-methodological (tests, questionnaires, observation). $\mathrm{E} \Delta \mathrm{A} \Lambda \Phi \mathrm{A}$ includes all of the above and more.

\section{Statistical Analysis}

Comparison between CARS, RAVEN, DTH, LC, and LE with each one of the E $\triangle \mathrm{A} \Lambda \Phi A$ variables (Pearson's $r$ ) showed strong and weak correlations with each one of the variables of E $\triangle \mathrm{A} \Lambda \Phi \mathrm{A}$ (see Tables 4-6).

Significant correlations were the following: CARS (negative correlation) with cognitive ability, language comprehension and language expression $(p<0.01)$ and with play $(p<0.05)$, RAVEN (positive correlation) with cognitive ability, language comprehension and language expression $(p<0.01)$ and with play $(p<0.05)$.

Language Comprehension (LC) (positive correlation) with cognitive ability, every day skills $(p<0.01)$ and other $(p<0.05)$; Language Expression (LE) (positive correlation) with cognitive ability, every day skills ( $p$ $<0.01)$ and play $(p<0.01)$.

Duration of therapy (DTH) (significant correlation) only with everyday skills and fine motor skills $(p<$ $0.02)$. 
Table 4

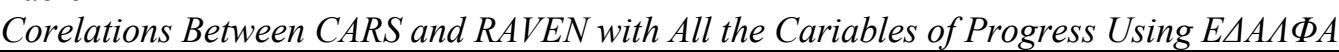

\begin{tabular}{|c|c|c|c|c|c|c|c|c|c|c|c|c|}
\hline & & CARS & RAVEN & $\alpha \delta 2-\alpha \delta 1$ & $\lambda \kappa 2-\lambda \kappa 1$ & $\gamma \nu 2-\gamma \nu 1$ & $\alpha \lambda 2-\alpha \lambda 1$ & $\varepsilon \lambda 2-\varepsilon \lambda 1$ & $\psi \alpha 2-\psi \alpha 1$ & $\delta \kappa \zeta 2-\delta \kappa \zeta 1$ & $\pi 2-\pi 1$ & $\alpha \lambda \lambda 2-\alpha \lambda \lambda 1$ \\
\hline \multirow{3}{*}{ CARS } & Pearson correlation & & -0.828 & -0.189 & -0.098 & -0.586 & -0.600 & -0.606 & -0.416 & -0.337 & -0.423 & -0.410 \\
\hline & Sig. (2-tailed) & & 0.000 & 0.317 & 0.608 & 0.000 & 0.000 & 0.000 & 0.018 & 0.059 & 0.016 & 0.020 \\
\hline & $\mathrm{N}$ & 32 & 32 & 30 & 30 & 32 & 32 & 32 & 32 & 32 & 32 & 32 \\
\hline \multirow{3}{*}{ RAVEN } & Pearson correlation & -0.828 & 1 & 0.114 & 0.147 & 0.573 & 0.539 & 0.576 & 0.360 & 0.274 & 0.446 & 0.411 \\
\hline & Sig. (2-tailed) & 0.000 & & 0.550 & 0.437 & 0.001 & 0.001 & 0.001 & 0.043 & 0.129 & 0.010 & 0.020 \\
\hline & $N$ & 32 & 32 & 30 & 30 & 32 & 32 & 32 & 32 & 32 & 32 & 32 \\
\hline
\end{tabular}

Table 5

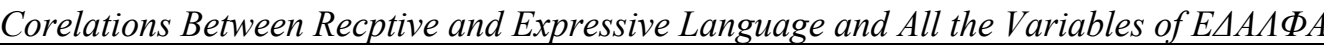

\begin{tabular}{llllllllll}
\hline & $\alpha \delta 2-\alpha \delta 1$ & $\lambda \kappa 2-\lambda \kappa 1$ & $\gamma \nu 2-\gamma \nu 1$ & $\alpha \lambda 2-\alpha \lambda 1$ & $\varepsilon \lambda 2-\varepsilon \lambda 1$ & $\psi \alpha 2-\psi \alpha 1$ & $\delta \kappa \zeta 2-\delta \kappa \zeta 1$ & $\pi 2-\pi 1$ & $\alpha \lambda \lambda 2-\alpha \lambda \lambda 1$ \\
\hline \multirow{6}{*}{$\alpha \lambda 2-\alpha \lambda 1$} & Pearson correlation & 0.282 & 0.496 & 0.687 & 1 & 0.713 & 0.475 & 0.586 & 0.485 \\
& Sig. (2-tailed) & 0.131 & 0.005 & 0.000 & & 0.000 & 0.006 & 0.000 & 0.005 \\
& $\mathrm{~N}$ & 30 & 30 & 32 & 32 & 32 & 32 & 32 & 32 \\
\hline \multirow{2}{*}{$\varepsilon \lambda 2-\varepsilon \lambda 1$} & Pearson correlation & 0.267 & 0.370 & 0.679 & 0.713 & 1 & 0.623 & 0.533 & 0.564 \\
& Sig. (2-tailed) & 0.154 & 0.044 & 0.000 & 0.000 & & 0.000 & 0.002 & 0.001 \\
& $N$ & 30 & 30 & 32 & 32 & 32 & 32 & 32 & 32 \\
\hline
\end{tabular}

Table 6

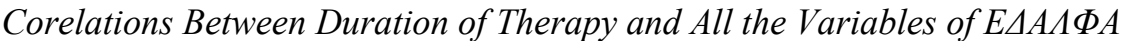

\begin{tabular}{|c|c|c|c|c|c|c|c|c|c|c|c|}
\hline & & Н $\Lambda 2-\mathrm{H} \Lambda 1$ & $\alpha \delta 2-\alpha \delta 1$ & $\lambda \kappa 2-\lambda \kappa 1$ & $\gamma v 2-\gamma v 1$ & $\alpha \lambda 2-\alpha \lambda 1$ & $\varepsilon \lambda 2-\varepsilon \lambda 1$ & $\psi \alpha 2-\psi \alpha 1$ & $\delta \kappa \zeta 2-\delta \kappa \zeta 1$ & $\pi 2-\pi 1$ & $\alpha \lambda \lambda 2-\alpha \lambda \lambda 1$ \\
\hline \multirow[t]{3}{*}{$\mathrm{H} \Lambda 2-\mathrm{H} \Lambda 1$} & Pearson correlation & 1 & 0.484 & 0.539 & 0.195 & 0.070 & 0.071 & 0.400 & 0.519 & 0.419 & 0.152 \\
\hline & Sig. (2-tailed) & & 0.007 & 0.002 & 0.285 & 0.703 & 0.698 & 0.023 & 0.002 & 0.017 & 0.408 \\
\hline & $N$ & 32 & 30 & 30 & 32 & 32 & 32 & 32 & 32 & 32 & 32 \\
\hline
\end{tabular}




\section{General Discussion}

In the present longitudinal 11 years study, we tried to investigate the co-occurring psychiatric problems that children with ASD under the age of four present, their speech language and feeding problems, the progress they made after intensive therapy, and the factors that influenced their progress the most.

The most common psychiatric problems were ADH (54\%). More children with average intelligence had ADH problems $(77.20 \%)$ as opposed to low functioning $(26.33 \%)$. A number of authors stress the co-occurrence of ADHD in children with ASD and place the incidence between $30 \%$ and $80 \%$ (Carrascosa-Romero \& De Cabo-De La Vega, 2015). Shared heritability (Rommelse, Frankle, \& Geurts, 2010) and shared endophenotypes (Holtman, Bölte, \& Pousta, 2007) could explain the high co-incidence. Anxiety was also common co-occurring difficulty (44\%). In a review of 31 studies involving 2,121 children and adolescents (Van Steensel, Bogels, \& Perrin, 2011), it was found that $39.6 \%$ of young people with ASD had at least one co-morbid DSM-IV anxiety disorder. Furthermore, in a study (Green, Ben-Sasson, Soto, \& Carter, 2012) with 149 toddlers with ASD and their mothers, assessed at 2 annual time points, it was found that a relationship between anxiety and SOR (sensory over responsivity) with anxiety symptoms increased over time while SOR remained relatively stable. In a study involving 88 children, 31 with ASD and 57 with typical development, 3 to 6 years old (Wilson, Manangan, Dauterman, \& Davis, 2014), children with ASD presented with more difficulties of ADHD and depression. In our study, low functioning children had smaller number of co-occurring problems and $20 \%$ had none. This finding has to be verified by other studies.

Regarding the speech and language problems, it was very interesting that all the children presented with receptive and expressive problems ranging from mild to severe, mostly severe. This finding challenges the DSM 5 that it considers speech and language problems associate rather than basic. In a study, which is in preparation, language problems remain even in high functioning children with ASD, who are enrolled in typical classes without support. They continue to have difficulties with grammar (conjunctions, prepositions) and pragmatics. The noticeable one was the high rate of dyspraxia (64\%). In a study of 17 children with ASD (Gernsbacher et al., 2008), 15\% presented with oral dyspraxia. Difficulty in oral movements at an early age was a negative factor in the development of speech (Iverson \& Wozniak, 2007; Page \& Boucher, 1998; Seal \& Bonvillion, 1997). Also, in a longitudinal study of seven years, Anderson et al. (2007) found that at the age of 9 years $29.7 \%$ of the children who participated in the study never developed speech. In two other studies (Cleland, Gibbon, Peppé, O'Hare, \& Rutherford, 2010; Rapin et al., 2009) 33\% of 3 to 9 years old children presented with delayed speech, phonological difficulties and speech disorders that remained even after therapy. Furthermore the percentage of children with ASD who present with feeding disorders reaches $46 \%$ to $89 \%$ (Ledford \& Gast, 2006; Kodak \& Piazza, 2008).

The present study showed also the progress children made, even those with global retardation. All children who were enrolled in therapy made considerable improvement. Autism severity, non-verbal intelligence and language skills (LC and LE) showed significant correlation with the progress children made. Intelligence and language comprehension had slightly higher correlations.

The relationship between intelligence and language skills on one hand and social skills and symptoms of autism on the other, have been demonstrated in a number of studies. Bennett et al. (2014) in a study of 330 children with ASD, 2 to 4 years old, which were divided into three groups (a) those with ASD and language deficits, (b) those with ASD and mental retardation, and (c) those with only ASD, found that children with 
ASD and language impairment were more socially impaired than those with only ASD but less impaired than those with ASD and mental retardation. In a study by Mayo, Chlebowski, and Eigsti (2013) with children with ASD, the age of utterance of first words (mainly when uttered before the age of two) foresaw their adjustable and cognitive skills. Furthermore, a study with 115 children, 2 to 3 years old (Ray-Sabramarian \& Weismer, 2012) showed negative relationship between the language comprehension and expression and the presence of stereotypes. Furthermore, progress in language skills was associated with fewer stereotypes.

\section{Conclusion}

Children with ASD even before the age of 4 years present with co-occurring psychiatric problems, particularly $\mathrm{ADH}$, anxiety, and irritation. High functioning children present with more problems, particularly ADH. All children presented with receptive and expressive language problems. A high number had dyspraxia. Oral dyspraxia was associated with absence of speech. With early intensive therapy all children made progress even those with global retardation. Intelligence and receptive language skills were highly correlated with progress.

\section{Limitations}

This was an unorthodox study that relied not only on tests but on therapist's judgment. It is time that therapist's clinical observation and critical opinions should have a voice in research. Those were children with definite ASD diagnosis because we worked with them for all those years. Tests for ages below 3 are not as reliable as $\mathrm{E} \triangle \mathrm{A} \Lambda \Phi \mathrm{A}$ which was created by the multidisciplinary team. Unfortunately the sample for the recording of progress was rather small, 32 children.

\section{References}

Andersen, P. N., Skogli, E. W., Hovik, K. T., Egeland, J., \& Oie, M. (2015). Associations among symptoms of autism, symptoms of depression and executive functions in children with high-functioning autism: A 2 Yrs. follow-up study. Journal of Autism and Developmental Disorders, 45(8), 2497-2507.

Anderson, D. K., Lord, C., Risi, S., Di Lavore, P. S., Thurm, A., Welch, K., \& Pickles, A. (2007). Patterns of growth in verbal abilities among children with autism spectrum disorder. Journal of Consulting and Clinical Psychology, 75(4), 594-604.

Arvedson, J., \& Brodsky, L. (2002). Pediatric swallowing and feeding: Assessment and management (2nd ed.). Albany, N.Y.: Singular Thomson Learning.

Bennett, T. A., Szatmari, P., Georgiades, K., Hanna, S., Janus, M., Georgiades, S., \& Bryson, S. (2014). Language impairment and early social competence in preschoolers with autism spectrum disorders: A comparison of DSM profiles. Journal of Autism and Developmental Disorders, 44(11), 2797-2808.

Ben-Itzchak, E., Watson, L. R., \& Zachor, D. A. (2014). Cognitive ability is associated with different outcome trajectories in autism spectrum disorders. Journal of Autism and Developmental Disorders, 44(9), 2221-2229.

Boucher, J. (2011). Language in autism spectrum disorders. In R. Illona and P. Rezaie (Eds.), Researching the autism spectrum: Contemporary perspectives. Cambridge University Press.

Bzoch, K. R., \& League, R. (2000). Receptive expressive emergent language test (REEL-3). Austin, M.N.: Pro-Ed.

Carrascosa-Romero, M. C., \& De Cabo-De La Vega, C. (2015). The comorbidity of adhd and autism spectrum disorders (ASDs) in community preschoolers. In J. M. Norvilitis (Ed.), Mental and behavioural disorders and diseases of the nervous system ADHD-“New directions in diagnosis and treatment". SBN 978-953-51-2166-4.

Carlsson, L. H., Norrelgen, F., Kjellmer, L., Westerlund, J., Gillberg, Ch., \& Fernell, E. (2013). Co-existing disorders and problems in preschool children with autism spectrum disorders. The Scientific World Journal, 6. Retrieved from http://dx.doi.org/10.1155/2013/213979

Cleland, J., Gibbon, F. E., Peppé, S. J. E., O’Hare, A., \& Rutherford, M. (2010). Phonetic and phonological errors in children with high function in autism and Asperger syndrome. International Journal of Speech Language pathology, 12(1), 69-76. 
Dawson, G., Rogers, S., Munson, J., Smith, M., Winter, J., Greenson, J., ... Varley, J. (2010). Randomized, controlled trial of an intervention for toddlers with autism: The early start Denver model. Pediatrics, 125(1), 17-23.

Eigsti, I. M., De Marchena, A. B., Schuh, J. M., \& Kelly, E. (2011). Language acquisition in autism spectrum disorders: A developmental review. Research in Autism Spectrum Disorders, 5, 681-691.

Gernsbacher, M. A., Sauer, E. A., Geye, H. M., Schweigert, E. K., \& Goldsmith, H. H. (2008). Infant and toddler oral- and manual-motor skills predict later speech fluency in autism. Journal of Child Psychology and Psychiatry, 49(1), 43-50.

Fernell, E., Eriksson, M. A., \& Gillberg, Ch. (2013). Early diagnosis of autism and impact on prognosis: A narrative review. Clin. Epidemiol, 5, 33-43. doi: 10.2147/CLEP.S41714

Fewell, R. R., \& Folio, M. R. (2000). Peabody developmental motor scales (2nd ed.). Austin: Pro Ed.

Green, S. A., Ben-Sasson, A., Soto, T. W., \& Carter, A. S. (2012). Anxiety and sensory over-responsivity in toddlers with autism spectrum disorders: Bidirectional effects across time. Journal of Autism and Developmental Disorders, 42(6), 1112-1119.

Hindley, C. B. (1960). The griffiths scale of infant development scores and predictions from 3 to 18 months. Journal of Child Psychology and Psychiatry, 1, 99-112.

Holtman, M., Bölte, S., \& Pousta, F. (2007). Attention deficit hyperactivity disorder symptoms in pervasive developmental disorders: Association with autistic behavior domains and coexisting psychopathology. Psychopathol, 40, 172-177. doi: $10.1159 / 000100007$

Hurdry, K., Chandler, S., Bedford, R., Pasco, G., Gliga, Th., Elsabbagh, M., ... Charman, T. (2014). Early language profiles in infants at high risk for autism spectrum disorder. Journal of Autism and Developmental Disorders, 44(1), 154-167.

Iverson, J. M., \& Wozniak, R. H. (2007). Variation in vocal-motor development in infant siblings of children with autism. Journal of Autism and Developmental Disorders, 37(1), 158-170.

Joshi, G., Faraone, S. V., Wozniak, J., Petty, C., Fried, R., Galdo, M., ... Biederman, J. (2014). Examining the clinical correlates of autism spectrum disorder in youth by ascertainment source. Journal of Autism and Developmental Disorders, 44(9), 2117-2126.

Kodak, T., \& Piazza, C. C. (2008). Assessment and behavioral treatment of feeding and sleeping disorders in children with autism spectrum disorders. Child \& Adolescent Psychiatric Clinics of North America, 17(4), 887-905.

Koegel, R. L., \& Koegel, L. K. (2006). Pivotal response treatments for autism: Communication, social \& academic development. Paul H. Brookes. Publishing Companies.

Kover, S. T., McDuffie, A. S., Hagerman, R. J., \& Abbeduto, L. (2013). Receptive vocabulary in boys with autism spectrum disorder: Cross-sectional developmental trajectories. Journal of Autism and Developmental Disorders, 43(11), 2696-2709.

Kotsopoulou, A., Georgiou, A., Gyftogianni, M., Gyftogianni, K., Sakellari, M., \& Florou, I. (2014). A tool for setting therapeutic goals by the multidisciplinary team for the preschool child with ASD (autism spectrum disorder). Psychology Research, 4(5), 354-336.

Ledford, J. R., \& Gast, D. L. (2006). Feeding problems in children with autism spectrum disorders: A review. Focus on Autism and Other Developmental Disabilities, 21(3), 153-166.

Levy, S. E., Giarelli, E., Lee, L. C., Schieve, L. A., Kirby, R. S., Cunniff, C., ...Rice, C. E. (2010). Autism spectrum disorder and co-occurring developmental, psychiatric, and medical conditions among children in multiple populations of the United States. Journal of Developmental and Behavioral Pediatrics, 31(4), 267-275.

Luyster, R., \& Lord, C. (2009). Word learning in children with autism spectrum disorders. Developmental Psychology, 45(6), 1774-1786.

Mayo, J., Chlebowski, C. D., \& Eigsti, I. M. (2013). Age of first words predicts cognitive ability and adaptive skills in children with ASD. Journal of Autism and Developmental Disorders, 43(2), 253-264.

Mecham, J. (1958). Verbal language development scale. In V. P. Roman (Ed.), The relationship between language ages of preschool children derived from a parent informant scale and language ages derived from tests administered directly to the preschool child. Language, Speech, and Hearing Services in Schools, 11, 50-55.

Mikita, N., Hollocks, M. J., Papadopoulos, A. S., Aslani, A., Harrison, S., Leibenluft, E., ... Stringaris, A. (2015). Irritability in boys with autism spectrum disorders: An investigation of physiological reactivity. Journal of Child Psychology and Psychiatry, 56(10), 1118-1126.

Mukaddes, N. M., Tutkunkardas, M. D., Sari, O., Aydin, A., \& Kozanoglu, P. (2014). Characteristics of children who lost the diagnosis of autism: A sample from Istanbul, Turkey. Autism Research and Treatment, 10. Retrieved from http://dx.doi.org/10.1155/2014/472120

Page, J., \& Boucher, J. (1998). Motor impairments in children with autistic disorder. Child Language Teaching and Therapy, 14(3). 
Plog, B. O., Banerjee, S., \& Brooks, P. J. (2011). Attention to Prosody (intonation) and content in children with autism and in typical children using spoken sentences in a computer game. Research in Autism Spectrum Disorders, 3(3), 743-758.

Ray-Subramanian, C. E., \& Weismer, S. E. (2012). Receptive and expressive language as predictors of restricted and repetitive behaviors in young children with autism spectrum disorders. Journal of Autism and Developmental Disorders, 42(10), 2113-2120.

Rapin, I., Dunn, M. A., Allen, D. A., Stevens, M. C., \& Fein, D. (2009). Subtypes of language disorders in school-age children with autism. Developmental Neuropsychology, 34(1), 66-84.

Rivard, M., Terroux, C., Mercier, C., \& Parent-Boursier, C. (2015). Indicators of intellectual disabilities in young children with autism spectrum disorders. Journal of Autism and Developmental Disorders, 45(1), 127-135.

Rogers, S., \& Dawson, G. (2010). Early start Denver model for young children with autism. The Gilford press New York/London.

Rogers, S. J., Vismara, L., Wagner, A. L., McCormick, C., Yang, G., \& Ozonoff, S. (2014). Autism treatment in the first year of life: A pilot study of infant start parent-Implemented intervention for symptomatic infants. Journal of Autism and Developmental Disorders, 44(12), 2981-2995.

Rommelse, N. N. J., Frankle, B., \& Geurts, H. M. S. (2010). Shared heritability of attention deficit/hyperactivity disorder and autism spectrum disorder. European Child and Adolescent Psychiatry, 19(3), 281-295.

Salazar, F., Baird, G., Chandler, S., Tseng, E., O’ sullivan, T., Howlin, P., ... Simonoff, E. (2015). Co-occuring psychiatric disorders in preschool and elementary school-aged children with autism spectrum disorder. Journal of Autism and Developmental Disorders, 45, 2283-2294.

Seal, B. C., \& Bonvillian, J. D. (1997). Sign language and motor functioning in students with autistic disorder. Journal of Autism and Developmental Disorders, 27(4), 437-466.

Tager-Flusberg, H., \& Kasari, C. (2013). Minimally verbal school-aged children with autism spectrum disorder: The neglected end of the spectrum. Autism Research, 6(6). Retrieved from http://10.1002/aur.1329

Tyson, K., Kelly, E., Fein, D., Orinstein, A., Troyb, E., Barton, M.,... Rosenthal, M. (2014). Language and verbal memory in individuals with a history of autism spectrum disorders who have achieved optimal outcomes. Journal of Autism and Developmental Disorders, 44(3), 648-663.

Van Steensel, F. J. A., Bogels, S. M., \& Perrin, S. (2011). Anxiety disorders in children and adolescents with autistic spectrum disorders: A meta-analysis. Clinical Child Psychology, 14(3), 302-317.

Vivanti, G., Dissanayake, C., \& the Victorian ASELCC Team. (2016). Outcome for children receiving the early start Denver model before and after 48 months. Journal of Autism and Developmental Disorders, 46(7), 2441-2449.

Weismer, S. E., \& Kover, S. T. (2015). Preschool language variation, growth, and predictors in children on the autism spectrum. Journal of Child Psychology and Psychiatry, 56(12), 1327-1337.

Wilson, B. J., Manangan, C. N., Dauterman, H. A., \& Davis, H. N. (2014). ADHD symptoms moderate the relation between ASD status and internalizing symptoms in 3-6 year-old children. Journal of Autism and Developmental Disorders, 44(6), $1347-1356$.

Zimmerman, I. L., Steiner, V. G., \& Pond, R. E. (1992). Preschool language scale-3 (PLS-3). San Antonio, T.X.: The Psychological Corporation. 